\title{
Simulação estocástica aplicada à análise temporal do nível potenciométrico no entorno da represa de Três Irmãos na área urbana da cidade de Pereira Barreto (SP) \\ Stochastic simulation applied to temporal analysis of the potentiometric level in the surroundings of the Três Irmãos dam located in the urban area of Pereira Barreto (State of São Paulo, Brazil)
}

\author{
Marcelo Monteiro da Rocha', Cláudio Benedito Baptista Leite ${ }^{2}$ e Ricardo Gerasimenko de Araújo ${ }^{1}$ \\ ${ }^{1}$ Universidade de São Paulo - USP, Instituto de Geociências, Rua do Lago, 562, Cidade Universitária, CEP 05508-080, \\ São Páulo, SP, Brasil (mmrocha@usp.br; geowally@bol.com.br) \\ ${ }^{2}$ Universidade Federal de São Paulo - UNIFESP, Diadema, SP, Brasil (cbbleite@gmail.com)
}

Recebido em 3 de junho de 2015; aceito em 8 de junho de 2016

\begin{abstract}
Resumo
O fechamento da barragem e a consequente formação do reservatório de Três Irmãos, em Pereira Barreto (SP), provocaram elevação do nível potenciométrico circunvizinho com implicações geotécnicas para o meio ambiente e a ocupação humana, oferecendo riscos que precisam ser mitigados. Dados provenientes de poços de controle, situados na cidade de Pereira Barreto, nas margens da represa, foram coletados em campanhas de monitoramento antes, durante e após o enchimento do reservatório, gerando um conjunto de superfícies potenciométricas empilhadas no tempo. Essa estruturação delineou uma análise espaço-temporal. A superfície potenciométrica foi modelada por simulação estocástica por bandas rotativas com a finalidade de fazer a análise de variância que utilizou duas simulações representando cenários opostos. O primeiro cenário foi o que apresentou o menor aumento do nível de água e outro, o maior. Tal fato resultou em um modelo tridimensional, demonstrando a progressão da elevação do nível de água, e possibilitou a observação de três períodos com comportamentos hidráulicos característicos e distintos: 1) uma situação inicial de equilíbrio hidráulico antes do enchimento; 2) momento de desequilíbrio e heterogeneidade durante o processo; 3) retomada do equilíbrio ao final do enchimento do reservatório. A análise algébrica de imagens também foi realizada por meio de um filtro definido para combinar os dois cenários e reforçar seus contrastes. A ação desse filtro gerou um mapa de variâncias que identificou duas regiões: uma de grande variação a centro-nordeste da área e uma região menos suscetível a variações a sudoeste da área investigada, respectivamente, as regiões de maior e menor variação do nível potenciométrico.
\end{abstract}

Palavras-chave: Simulação por bandas rotativas; Geoestatística; Nível potenciométrico; Análise temporal.

\begin{abstract}
The filling of the reservoir of Três Irmãos in Pereira Barreto (State of São Paulo, Brazil) caused the rise of the surrounding potentiometric level with geotechnical implications to the environment and to human occupation, imposing risks that must be mitigated. Data from control wells located along the reservoir banks were collected during monitoring campaigns before, during and after the reservoir filling, generating a set of potentiometric surfaces over time. This structure outlined a spatial-temporal analysis. The potentiometric surface was modeled by turning bands stochastic simulation in order to perform the analysis of variance using two simulations that represent opposite scenarios. The first scenario showed the lowest water level rise and the second showed the highest water level rise. This resulted not only in a three-dimensional model for water level rises but also allowed the interpretation of three periods of distinct and characteristic hydraulic behaviors: 1) an initial state of hydraulic equilibrium before the filling of the reservoir, 2) a momentary disequilibrium and heterogeneity during filling, and 3) the regaining of the balance when filling was completed. The algebraic analysis of the images was also performed by means of a filter defined to combine the two scenarios and enhance their contrasts. The application of this filter generated a map of variances that highlighted two regions: one with a wide variation located in the center-northeast of the area and another less susceptible to variations located southwest of the study area, respectively regions of highest and lowest potentiometric level variations.
\end{abstract}

Keywords: Turning bands simulation; Geostatistics; Potentiometric level; Spatio-temporal analysis. 


\section{INTRODUÇÃO}

As novas condições de equilíbrio da superfície potenciométrica de um aquífero livre no entorno de reservatórios formados pelo barramento de rios podem causar impactos significativos sobre diversos aspectos ambientais de uma bacia hidrográfica, dentre eles efeitos adversos associados à colapsividade dos solos, induzindo problemas pertinentes às condições de equilíbrio das fundações e estruturas das construções mais próximas ao limite do futuro reservatório, a saturação de solos superficiais, ocasionando o afogamento de raízes e possibilitando a salinização, diminuindo, assim, a capacidade de produção agrícola da área, além da formação de nascente e lagoas em zonas topograficamente mais deprimidas (Albuquerque Filho e Leite, 2002).

A presença de áreas urbanas nas proximidades dos reservatórios pode potencializar problemas, dada a complexidade das ocupações (estruturas enterradas como canalizações de água e esgoto, redes de eletrificação e telefonia, pavimentação de ruas, extensos pátios, cemitérios, fossas sépticas, cacimbas, hortas, edifícios habitacionais ou comerciais, tanques enterrados etc.), exigindo previsões de caráter quantitativo dos impactos esperados.

A implantação de um reservatório em um vale, que atua naturalmente como área de descarga regional, produz tanto um reajuste transitório quanto mudanças permanentes no sistema hidrogeológico adjacente ao reservatório. Durante o enchimento do reservatório, um sistema de fluxo transitório é induzido em suas áreas marginais. Como as cargas hidráulicas nas bordas do reservatório sofrem elevações, ocorrem inversões nas direções de fluxo e temporariamente o fluxo que se estabelece é do reservatório para o sistema aquífero.

O resultado final do reajuste transitório inicial é a alteração permanente, a longo prazo, do regime hidrogeológico regional. Os níveis de água são elevados, as cargas hidráulicas do aquífero são aumentadas, porém os gradientes hidráulicos são suavizados, provocando a elevação e o aplainamento da superfície potenciométrica, com redução das descargas de base nos exutórios naturais em relação à situação original (Medovar e Akhmetyeva, 1984; IPT, 1983).

Diante dos impactos potenciais, estudos de caráter observacional e preditivo podem fornecer subsídios básicos e fundamentais para elaborar medidas preventivas ou emergenciais que eventualmente se mostrem necessárias, a partir do período de início do enchimento do reservatório.

O conhecimento das condições iniciais da superfície potenciométrica do aquífero livre em todo o domínio analisado é complexo e difícil de ser obtido, além de que os fenômenos envolvidos estão associados a tempos longos de respostas. Assim, para estimar ou interpolar valores potenciométricos em todo o domínio, utilizam-se técnicas de amostragem cujas informações podem fornecer subsídios para o tratamento e a consolidação do entendimento da potenciometria para todo o domínio.

Neste trabalho, as cotas do nível freático no entorno da barragem de Três Irmãos, junto à cidade de Pereira Barreto, no noroeste do estado de São Paulo, foram utilizadas para estimar a superfície potenciométrica por simulação estocástica e realizar uma análise de variação do nível potenciométrico, de modo a identificar os locais mais afetados pela elevação do nível freático no entorno da barragem. Os cálculos envolveram não apenas as condições iniciais e finais da superfície potenciométrica, mas também as condições intermediárias entre o início e o final do enchimento do lago, conferindo características temporais às simulações.

A coleta de informações do nível potenciométrico iniciou-se antes do fechamento da barragem e perdurou por aproximadamente oito anos, até a total formação e estabilização do lago. Essa amostragem foi planejada e realizada com o estabelecimento de 186 poços de monitoramento distribuídos em malha irregular por toda a área de estudo (área urbana do município de Pereira Barreto, SP).

\section{LOCALIZAÇÃO E CARACTERIZAÇÃO DA ÁREA}

A cidade de Pereira Barreto localiza-se na região noroeste do estado de São Paulo. Pode-se chegar, a partir da capital, pela rodovia dos Bandeirantes (SP-348) até o município de Cordeirópolis, a partir do qual se toma a rodovia Washington Luís (SP-310) até a referida cidade. Outra rota possível inicia-se na rodovia Castelo Branco (SP-280) até a cidade de Botucatu e, em seguida, acessa-se a rodovia Marechal Rondon (SP-330) até Pereira Barreto. Ambas as rotas podem ser observadas na Figura 1 (croquis de localização do município e principais rotas de acesso).

Na região deste estudo, a geologia é representada pelas Formações Rio Paraná e Santo Anastácio, ambas do Grupo Caiuá, e pelo Grupo Bauru. Os sedimentos que compõem essas unidades encontram-se sobrepostos aos basaltos da Formação Serra Geral e sotopostos a sedimentos terciários e quaternários (Leite, 2005).

O sistema aquífero livre regional é constituído por um pacote composto de aluviões, coluviões, solo de alteração de arenito, arenito e solo de alteração de basalto; eventualmente, algumas dessas unidades não estão presentes em determinadas regiões. O substrato semi-impermeável a impermeável é formado pelos basaltos da Formação Serra Geral. As espessuras médias desse sistema variam entre 50 e $150 \mathrm{~m}$, com tendência de aumento, a partir da calha do Rio Tietê para os divisores norte e sul, mostrando o condicionamento destes à morfologia da superfície e, subordinadamente, ao maciço rochoso basáltico (Leite, 2005). 


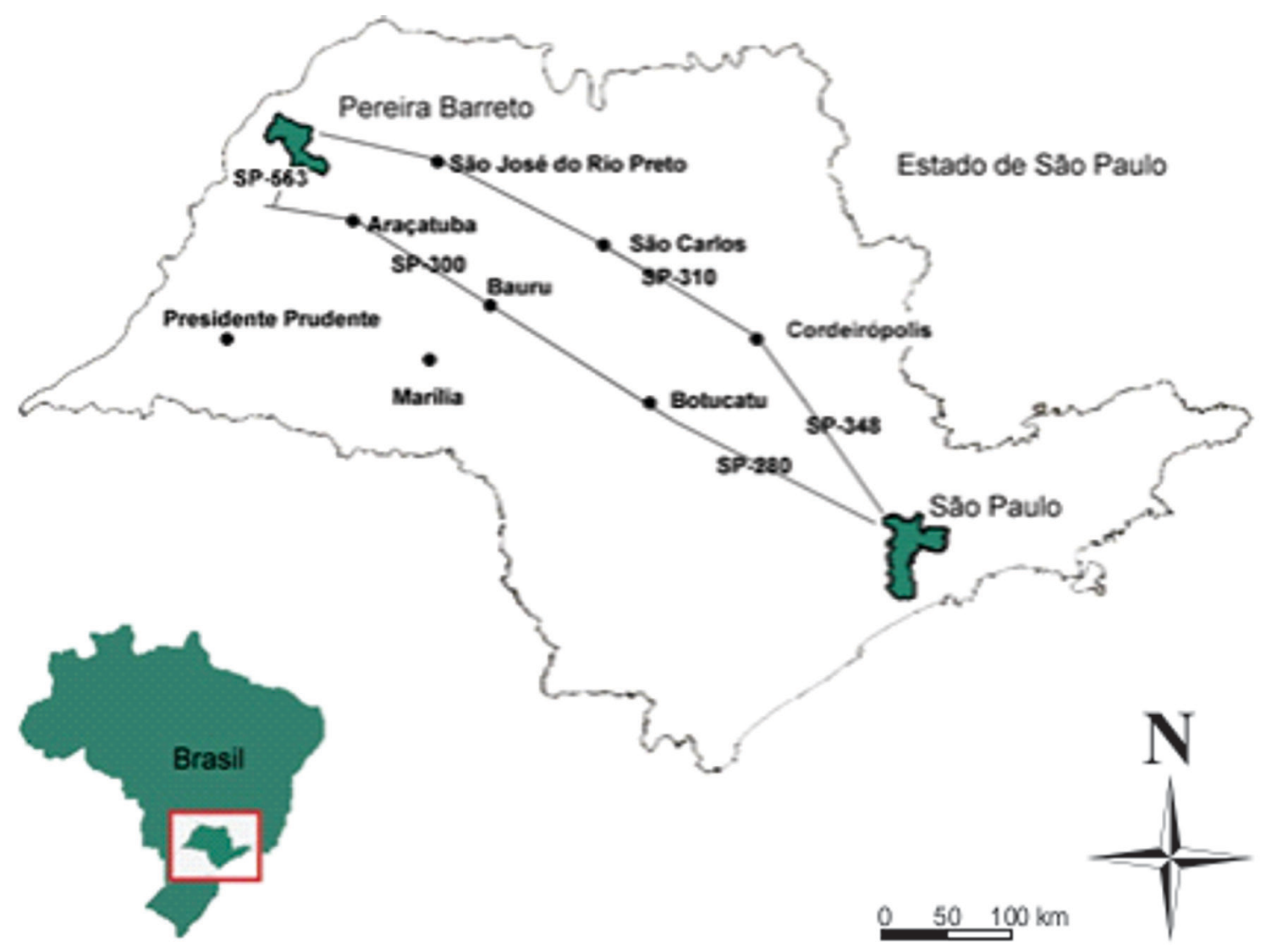

Figura 1. Localização e rotas de acesso à área de estudo a partir da cidade de São Paulo, SP.

\section{BASE DE DADOS}

Para este estudo, a base de dados foi constituída pelas informações: nome, coordenadas UTM e cota do nível de água do ponto, em 186 poços de monitoramento, coletadas entre outubro de 1987 e março de 1999, durante as fases anterior, concomitante e posterior à construção da Usina Hidrelétrica, distribuídos em malha irregular no entorno do reservatório da barragem de Três Irmãos - área urbana do município de Pereira Barreto, SP (Figura 2).

As campanhas de monitoramento para medir as cotas potenciométricas se realizaram a intervalos de tempo não regulares ao longo de 62 visitas de campo, com intervalo médio entre as medições de 45 dias. Observa-se na base de dados que, com o passar do tempo, alguns poços submergiram com a formação do reservatório, outros foram aterrados e não foram realizadas medições em todos os poços, em todas as campanhas, resultando na ausência de medidas em certos poços em determinados períodos.

Os dados de campo foram compilados e organizados de modo a constituir uma base única, em que as leituras foram sucessivamente empilhadas. O resultado dessa organização fez os dados se assemelharem a perfis de sondagem, onde as cotas dos níveis de água das campanhas de medições realizadas antes do fechamento da barragem/formação do reservatório fossem equivalentes às cotas mais profundas dos níveis de água nos poços de monitoramento.

A Figura 3 ilustra o modelo de blocos com a disposição das superfícies potenciométricas empilhadas em cada uma das seleções realizadas em azul, assim como as superfícies de tendência representadas pelo contorno em vermelho com traçado mais espesso.

Com poços apresentando períodos sem informações e ainda com campanhas de medição realizadas a intervalos de tempo variáveis, realizou-se a regularização dessas amostras para que os intervalos de amostragem fossem constantes. Optou-se por utilizar intervalos de 45 dias, pois esse foi o tempo médio entre as campanhas de monitoramento. Os trechos regularizados inferiores a dez dias não foram considerados. Pode-se verificar a distribuição espacial dos poços na Figura 4.

Os variogramas experimentais calculados para esses dados apresentaram-se não estacionários, interpretando-se essa característica como sendo componente de deriva regional. Desse modo, como em Leite (2005) e Lourenço (2005), optou-se por tratar a deriva ou retirá-la, utilizando superfícies de tendência e analisar e estimar os resíduos obtidos da superfície ajustada. Essa análise foi realizada 


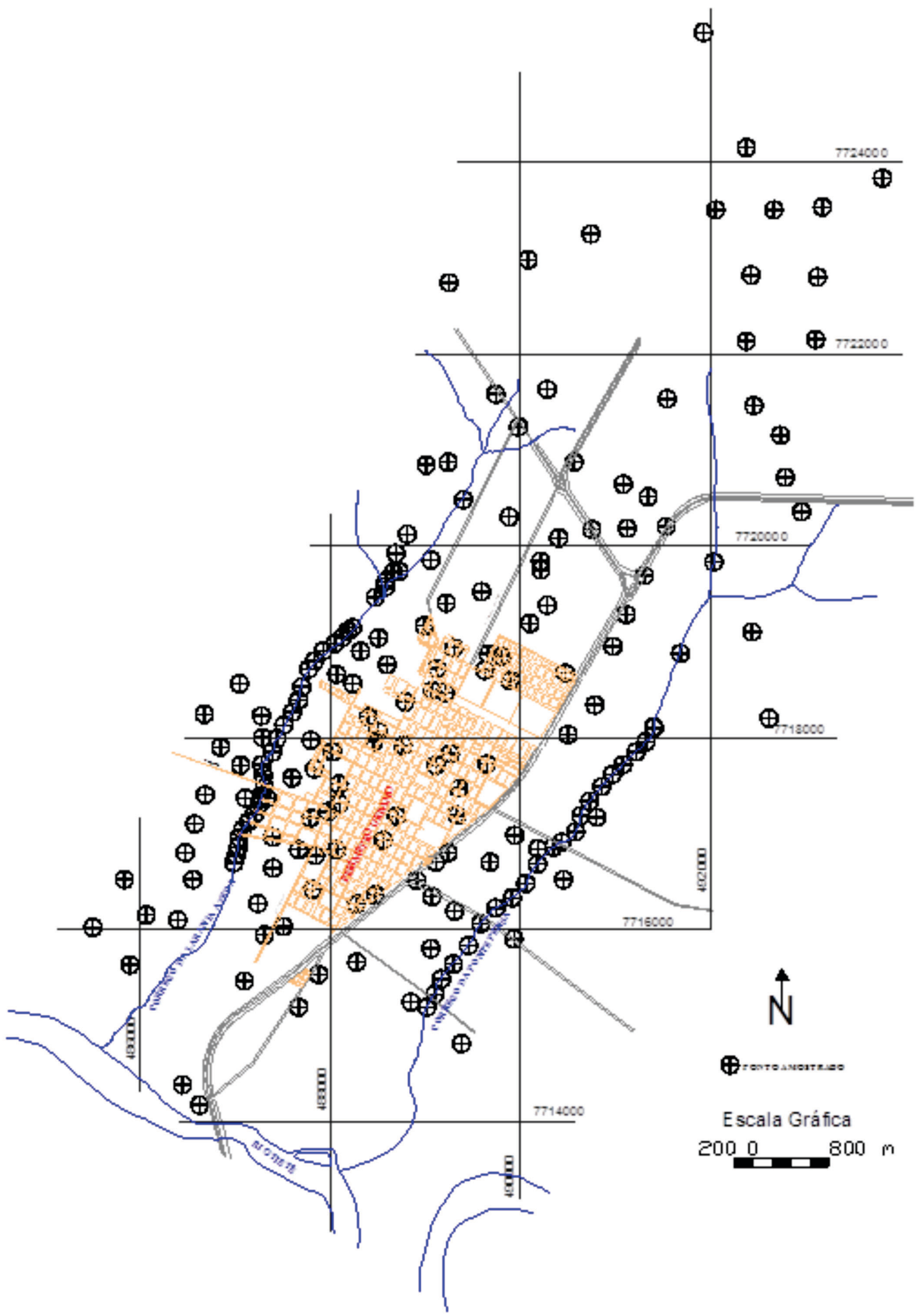

Figura 2. Mapa da distribuição dos pontos (Rocha et al., 2007). 


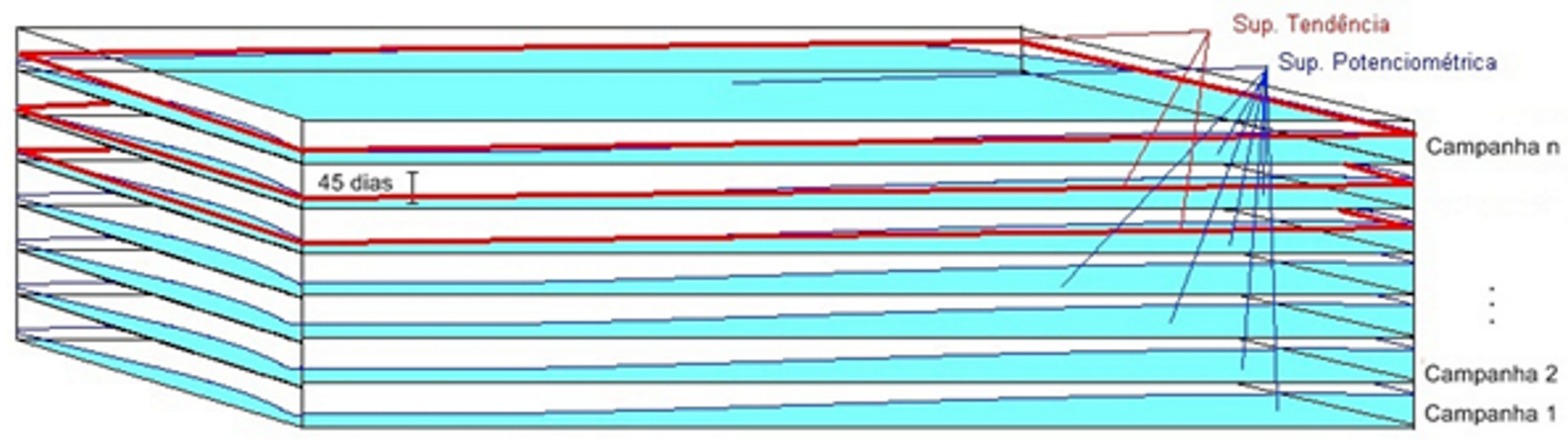

Figura 3. Empilhamento das campanhas com as superfícies de tendência ajustadas a cada seleção.

(A)

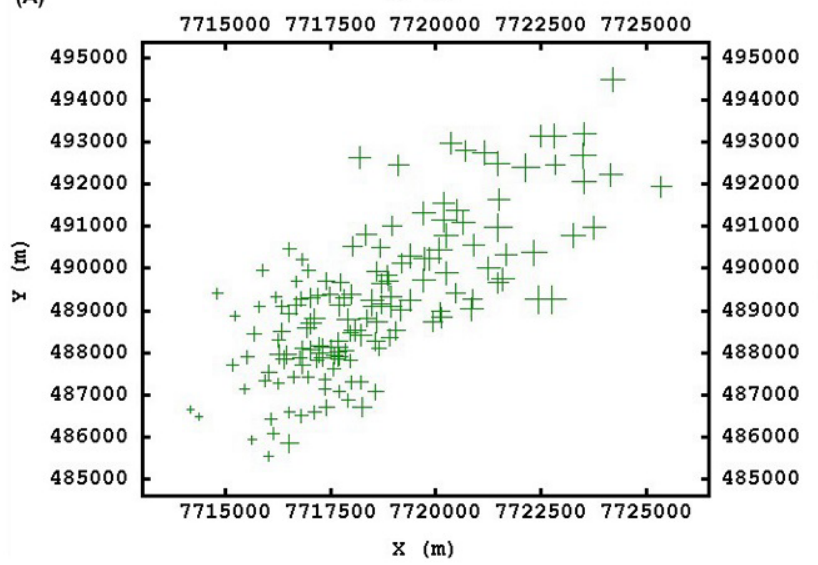

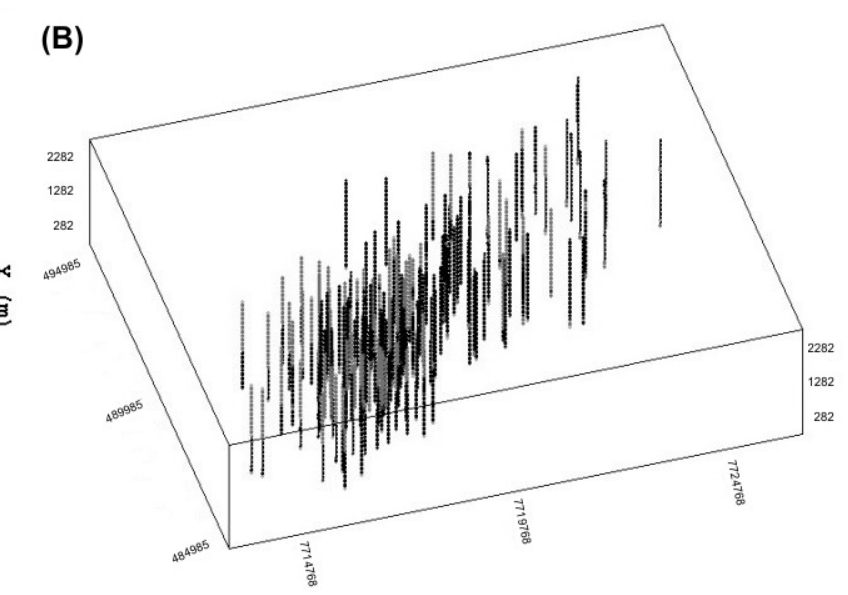

Figura 4. A) Mapa base com a espacialização dos poços de monitoramento; B) Perspectiva do intervalo de tempo entre o início e o final das medições realizadas nos poços.

inicialmente para os dados em três dimensões, porém a superfície resultante não foi representativa do fenômeno. Os dados foram separados em campanhas de 45 dias para que as superfícies de tendência fossem ajustadas individualmente a cada campanha. A Figura 3 ilustra as superfícies de tendência (traço espesso) ajustadas às superfícies potenciométricas individualizadas.

Os resíduos calculados foram transformados para seguir uma distribuição gaussiana normal, por anamorfose gaussiana. Esses dados foram analisados e as estatísticas básicas, calculadas, assim como os variogramas experimentais, utilizando-se os conceitos da análise exploratória preconizada por autores como Deutsch e Journel (1992), Armstrong (1998), Yamamoto (2001), entre outros.

\section{RESULTADOS OBTIDOS}

A seguir, os principais resultados obtidos. São eles: análise estatística, geoestatística, análise dos resíduos, anamorfose gaussiana, simulação estocástica e tratamento algébrico.

\section{Análise estatística dos dados potenciométricos}

As estatísticas descritivas foram calculadas para os dados em seu estado bruto regularizados, obtendo-se os valores mostrados na Tabela 1.

Na Figura 5, histograma dos dados, observa-se suave assimetria, confirmada pelo coeficiente de assimetria (CA). Porém, analisando-se o gráfico com mais atenção, pode-se inferir a presença de duas populações distintas sobrepostas, aquela onde predominam cotas menores, abaixo de $325 \mathrm{~m}$, e outra assimétrica positiva, onde predominam as cotas potenciométricas entre 325 e $375 \mathrm{~m}$, caracterizando dois grupos de cotas, um a NE da área e outro a SW. As cotas abaixo de $325 \mathrm{~m}$ estão associadas a uma topografia praticamente plana, na margem do rio, enquanto as cotas acima de $325 \mathrm{~m}$ estão na encosta da colina.

Nas Figuras 6 e 7, podem ser observadas as distribuições das populações 1 (Figura 6) e 2 (Figura 7) presentes no mapa de pontos. Nota-se que a população 1 destacada como quadrados a sudoeste da área (Figura 6B) possui distribuiç̧ão que tende à simétrica (Figura 6A), enquanto a população 
2 representada por quadrados a nordeste (Figura 7B) apresenta assimetria positiva (Figura 7A).

\section{Variograma experimental dos dados brutos}

Os variogramas calculados dos dados das cotas potenciométricas brutas apresentam comportamento crescente com a distância, o que, segundo Kitanidis (1997),

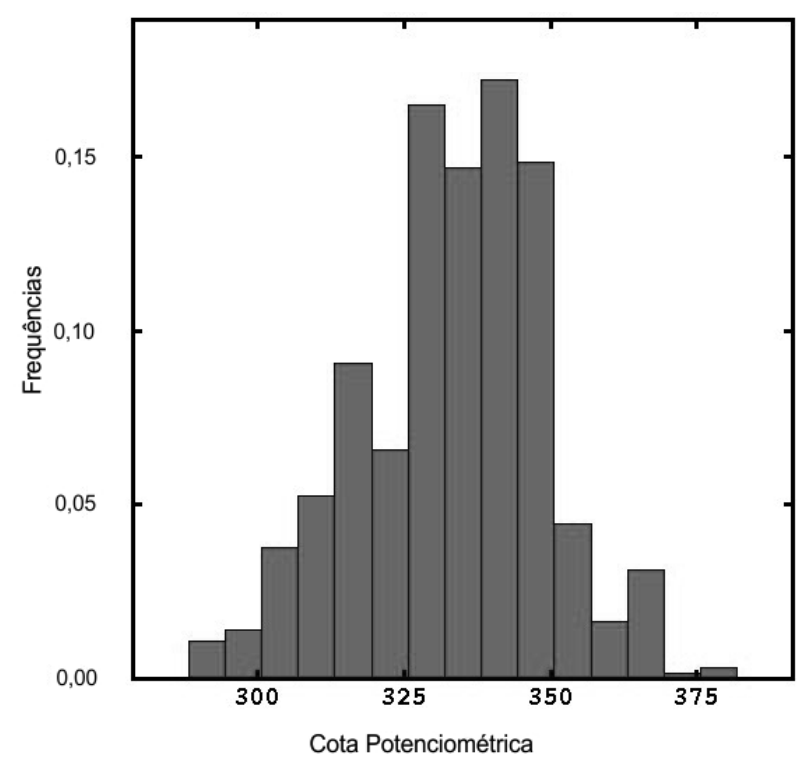

Figura 5. Histograma original dos dados potenciométricos. é um comportamento típico de variáveis potenciométricas caracterizadas pela alta continuidade de valores em terreno homogêneo.

Na Figura 8, apresenta-se o variograma experimental dos dados originais em três direções. Observe que são não estacionários por não apresentarem patamares definidos.

A análise exploratória indica a presença de anisotropia no domínio. As direções N45 e N135 apresentam as maiores diferenças entre as direções observadas para os dados potenciométricos originais.

O variograma não estacionário obtido para os dados potenciométricos não pode ser usado para a simulação estocástica, pois requer estacionariedade de segunda ordem.

Desse modo, foi retirada a deriva encontrada por meio de um tratamento de resíduos, com o ajuste, por mínimos quadrados, de superfícies de tendência representadas por polinômios de grau 1.

\section{Resíduos}

A retirada da deriva através das superfícies de tendência ajustadas para cada seleção gerou um conjunto de dados de resíduos. Na Tabela 2, constam as estatísticas do conjunto completo dos resíduos e, na Figura 9, sua distribuição de frequências em um histograma.

O CA caracteriza uma distribuição assimétrica levemente negativa dos desvios dos dados potenciométricos em relação a todas as superfícies de tendência ajustadas; porém, pela forma da distribuição observada na Figura 9, pode-se assumir a distribuição como simétrica.
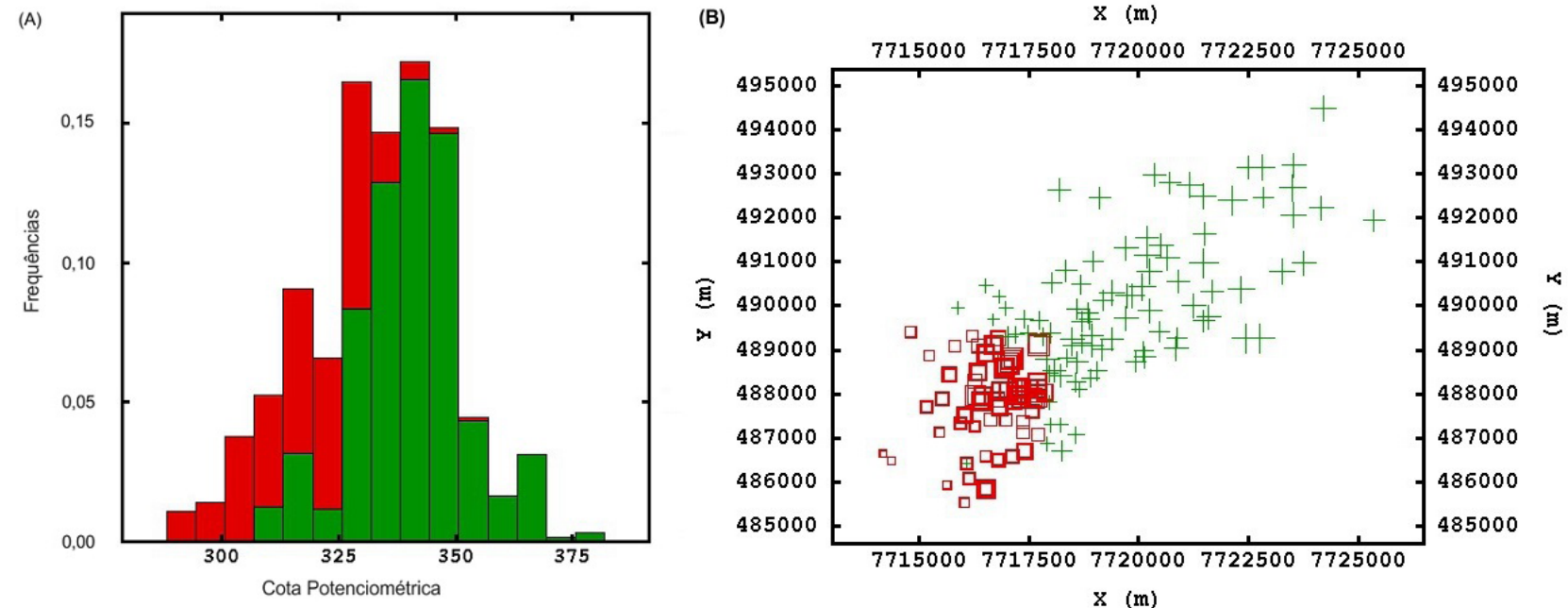

Figura 6. A) Histograma dos dados da população 1; B) Posicionamento da população 1 situada a sudoeste do mapa base representada por quadrados pequenos. O tamanho dos quadrados é proporcional ao valor da cota potenciométrica.

Tabela 1. Estatísticas descritivas do conjunto de dados.

\begin{tabular}{cccccccccc}
\hline $\mathbf{n}$ & Mín & Máx & Média & s & Var(x) & CA & $\mathbf{Q ( 2 5 \% )}$ & $\mathbf{M}$ & $\mathbf{Q ( 7 5 \% )}$ \\
\hline 5615 & 288,20 & 381,89 & 332,98 & 15,67 & 249,43 & $-0,21$ & 323,46 & 333,76 & 344,33 \\
\hline
\end{tabular}


Tabela 2. Estatísticas descritivas para os dados de resíduos obtidos após o ajuste das superfícies de tendência.

\begin{tabular}{cccccccccc}
\hline $\mathbf{n}$ & Mín & Máx & Média & $\mathbf{s}$ & $\mathbf{V a r}(\mathbf{x})$ & $\mathbf{C A}$ & $\mathbf{Q ( 2 5 \% )}$ & $\mathbf{M}$ & $\mathbf{Q ( 7 5 \% )}$ \\
\hline 5615 & $-42,11$ & 31,30 & 0 & 8,05 & 64,76 & $-0,37$ & $-4,25$ & $-0,17$ & 5,38 \\
\hline
\end{tabular}

n: número de amostras; Mín: valor mínimo; Máx: valor máximo; s: desvio-padrão; Var(x): variância; CA: coeficiente de assimetria; Q: quartil; M: mediana.

(A)

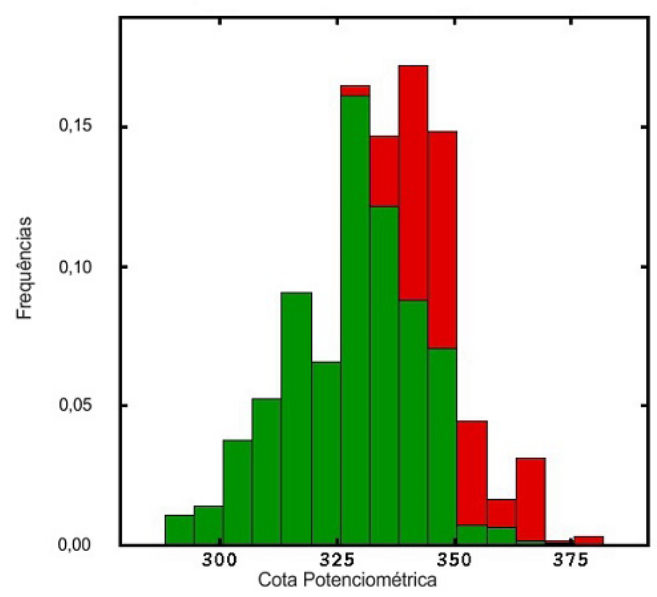

(B)

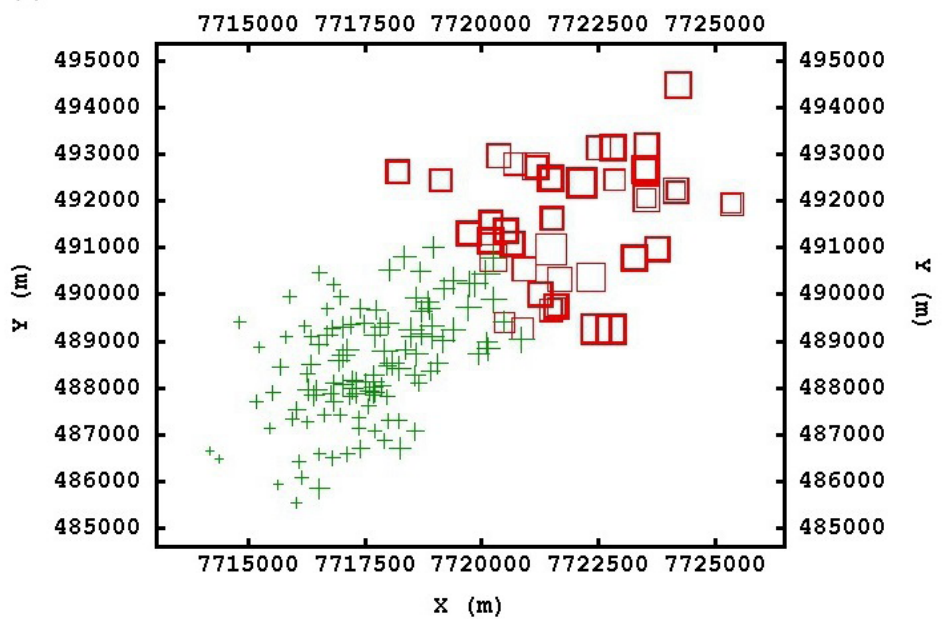

Figura 7. A) Histograma dos dados da população 2; B) Posicionamento da população 2 situada a sudoeste do mapa base representada por quadrados pequenos. O tamanho dos quadrados é proporcional ao valor da cota potenciométrica.

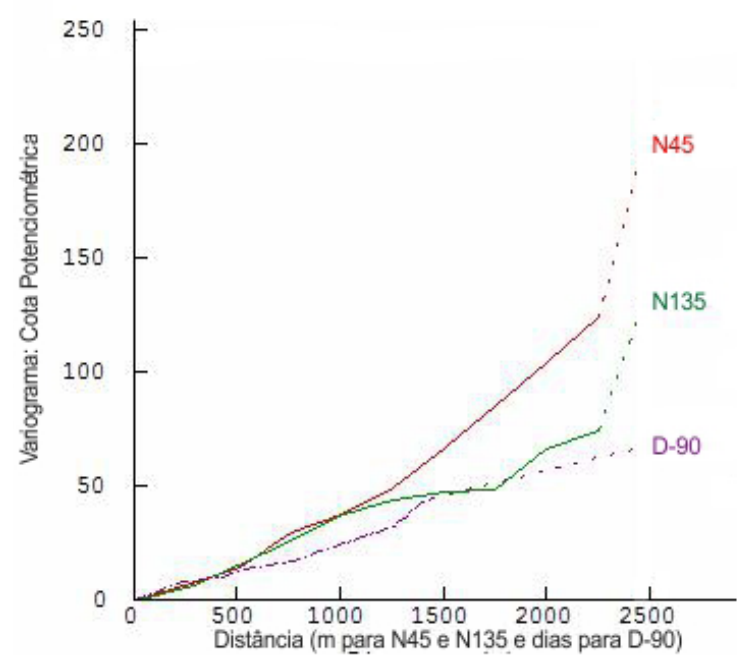

Figura 8. Variograma experimental calculado para as direções de $45^{\circ}, 135^{\circ}$ e vertical.

\section{Anamorfose gaussiana}

A anamorfose gaussiana requer dados multigaussianos. $O$ teste de bigaussianidade gerou os diagramas de dispersão de $\mathrm{Z}(\mathrm{X})$ versus $\mathrm{Z}(\mathrm{X}+\mathrm{h})$ mostrados nas Figuras $10 \mathrm{~A}$, B.

Esse teste foi realizado para o bloco das cotas potenciométricas brutas (Figura 10A) e dos resíduos de uma das campanhas selecionadas (Figura 10B).

A distribuição não linear das nuvens de dispersão demonstra independência entre as variáveis $\mathrm{X}$ e $\mathrm{X}+\mathrm{h}$,

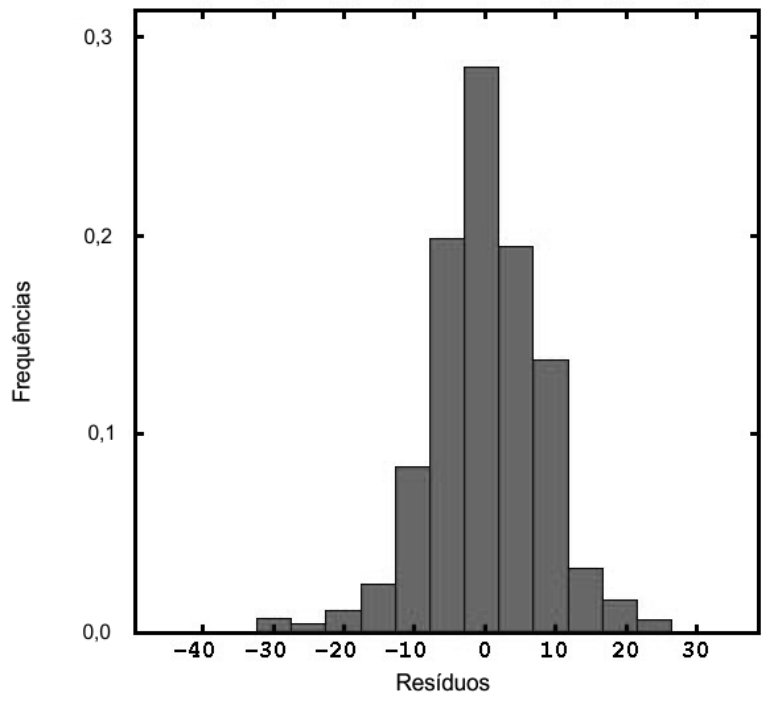

Figura 9. Histograma dos resíduos.

confirmando a hipótese de distribuição bigaussiana. Desse modo, a anamorfose gaussiana pôde ser realizada.

As estatísticas descritivas para os dados de resíduos transformados pela anamorfose gaussiana por inversão de interpolação linear encontram-se na Tabela 3.

$\mathrm{Na}$ Tabela 3, observam-se média igual a zero (média $=0$ ), CA próximo de zero e variância próxima de 1 , podendo ser considerada distribuição gaussiana normal $(\mathrm{N}[0,1])$. O histograma da distribuição dos dados de resíduos transformados pode ser visto na Figura 11. 
Tabela 3. Estatísticas descritivas para os dados de resíduos transformados.

\begin{tabular}{cccccccccc}
\hline $\mathbf{n}$ & Mín & Máx & Média & $\mathbf{s}$ & Var(x) & $\mathbf{C A}$ & $\mathbf{Q ( 2 5 \% )}$ & $\mathbf{M}$ & $\mathbf{Q ( 7 5 \% )}$ \\
\hline 5615 & $-3,12$ & 2,88 & 0 & 0,99 & 0,99 & 0,02 & $-0,66$ & 0,01 & 0,67 \\
\hline
\end{tabular}

n: número de amostras; Mín: valor mínimo; Máx: valor máximo; s: desvio-padrão; Var(x): variância; CA: coeficiente de assimetria; Q: quartil; M: mediana.
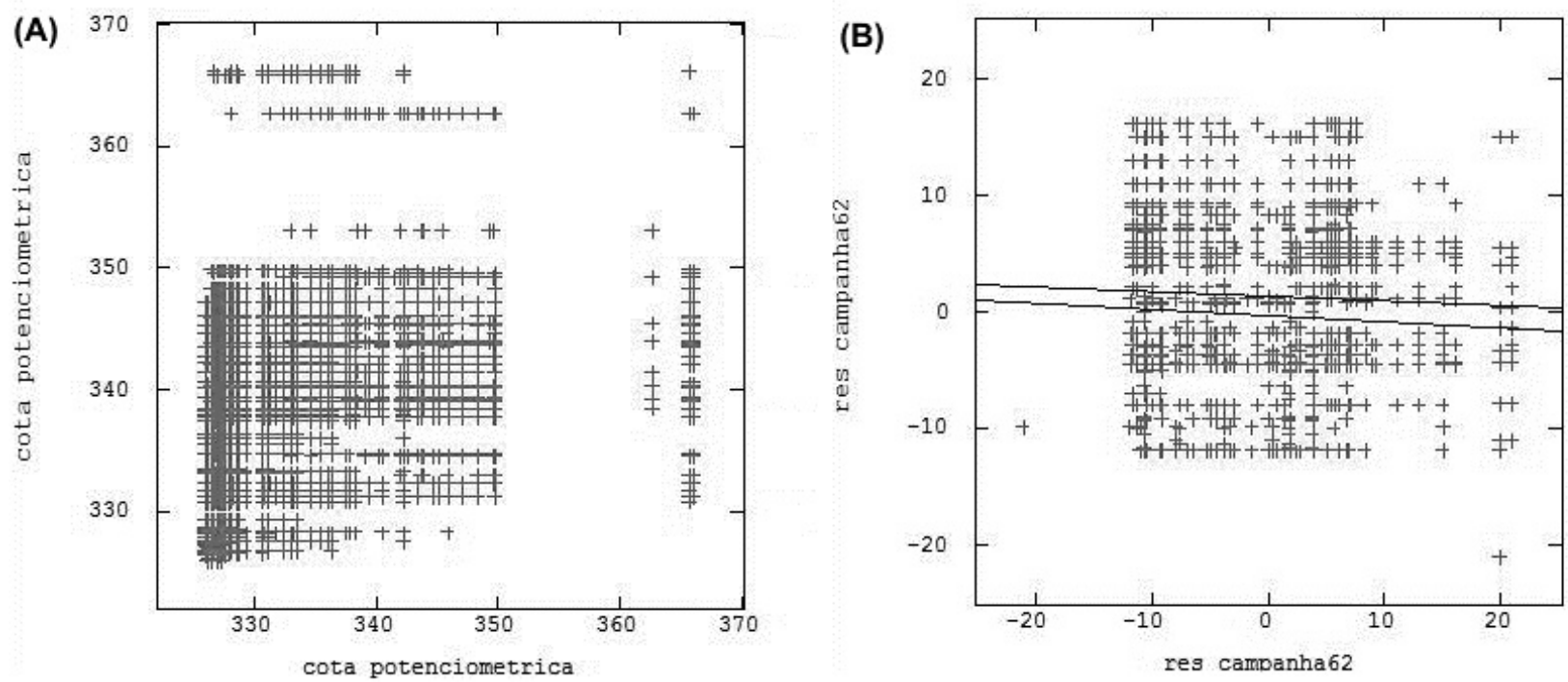

Figura 10. Gráficos de dispersão $Z(X)$ versus $Z(X+h)$ mostrando o teste de bigaussianidade para o bloco dos dados de cotas potenciométricos brutas $(A)$ e dos resíduos $(B)$.

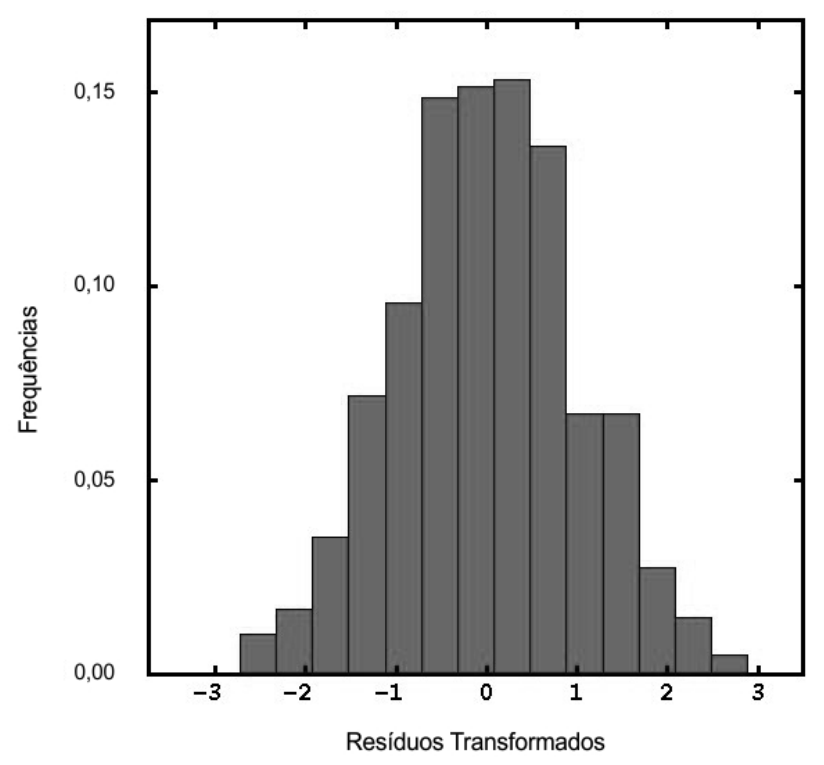

Figura 11. Distribuição dos dados de resíduos transformados.

Após a anamorfose gaussiana, o variograma foi calculado e ajustado individualmente para cada campanha de amostragem e, então, utilizado no cálculo do variograma médio para as duas direções $45^{\circ}$ e $135^{\circ}$. Aos variogramas experimentais foram ajustados modelos gaussianos. A Figura 12A-C apresenta os variogramas calculados e seus respectivos modelos.
Na Tabela 4, constam os parâmetros de cada uma das direções calculadas nos variogramas experimentais e a Tabela 5 mostra os parâmetros dos modelos ajustados.

A validação cruzada do variograma médio indicou um ajuste satisfatório e ajudou a definir os parâmetros de vizinhança. O coeficiente de correlação obtido foi de 0,993. A Figura 13 é o diagrama de dispersão resultante da validação.

\section{Simulação estocástica}

Foram escolhidas, dentre as cem simulações realizadas por bandas rotativas, as de maior e as de menor média, assumindo-se serem estas as realizações de pior e melhor cenários. A Tabela 6 apresenta as estatísticas dos dados das simulações na realização $n^{\circ} 18$, com cota potenciométrica média de $336,70 \mathrm{~m}$, e na realização $\mathrm{n}^{\circ} 65$, com cota potenciométrica média de $334,61 \mathrm{~m}$.

A Figura 14A, B apresenta os mapas gerados, respectivamente, da realização $n^{\circ} 18$ e da realização $n^{\circ} 65$ e que representam o início do processo de enchimento do reservatório.

A Figura 15A, B apresenta os mapas gerados para as mesmas realizações, porém representando o término do processo de enchimento do reservatório.

Comparando as Figuras 14 e 15, verifica-se um processo de aumento do nível potenciométrico partindo de uma distribuição claramente bimodal para uma distribuição unimodal, em que a distribuição das cotas tende a variar 


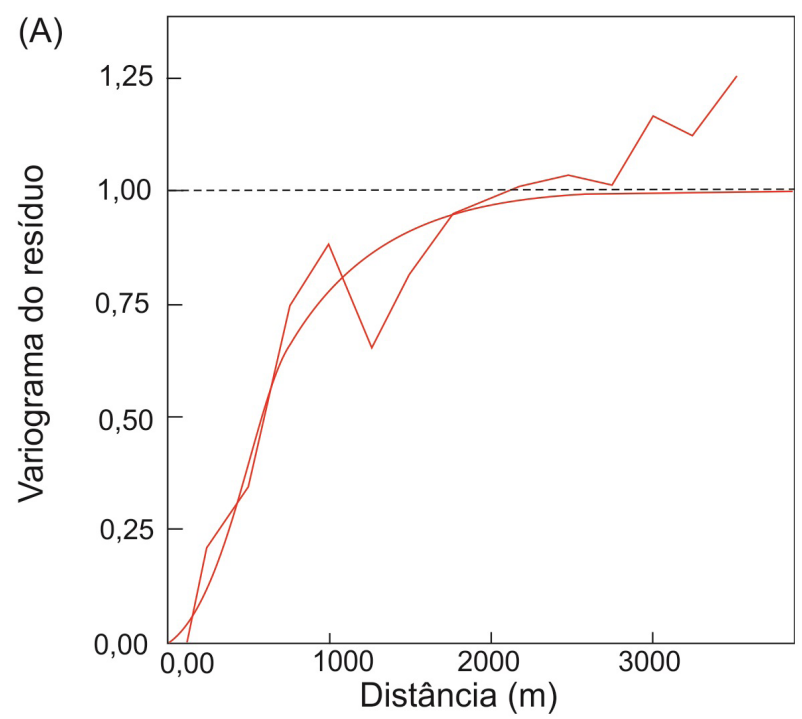

Tabela 4. Parâmetros calculados para os variogramas experimentais nas direções N45, N135 e D-90.

\begin{tabular}{ccccc}
\hline Direção & $\begin{array}{c}\text { Tolerância } \\
\text { ang. }\end{array}$ & Passo & $\begin{array}{c}\mathbf{N}^{\circ} \text { de } \\
\text { passos }\end{array}$ & Tolerância \\
\hline N45 & $22,5^{\circ}$ & $250 \mathrm{~m}$ & 15 & $50 \%$ \\
N135 & $22,5^{\circ}$ & $250 \mathrm{~m}$ & 15 & $50 \%$ \\
D-90 & $45^{\circ}$ & 45 dias & 28 & $50 \%$ \\
\hline
\end{tabular}

Tabela 5. Parâmetros de ajuste para o modelo nas direções N45, N135 e D-90.

\begin{tabular}{cccc}
\hline Direção & Modelo & Amplitude & Patamar \\
\hline N45 & & $700 \mathrm{~m}$ & 1,0 \\
N135 & Gaussiano & $1200 \mathrm{~m}$ & 1,0 \\
D-90 & & 1100 dias & 0,6 \\
\hline
\end{tabular}
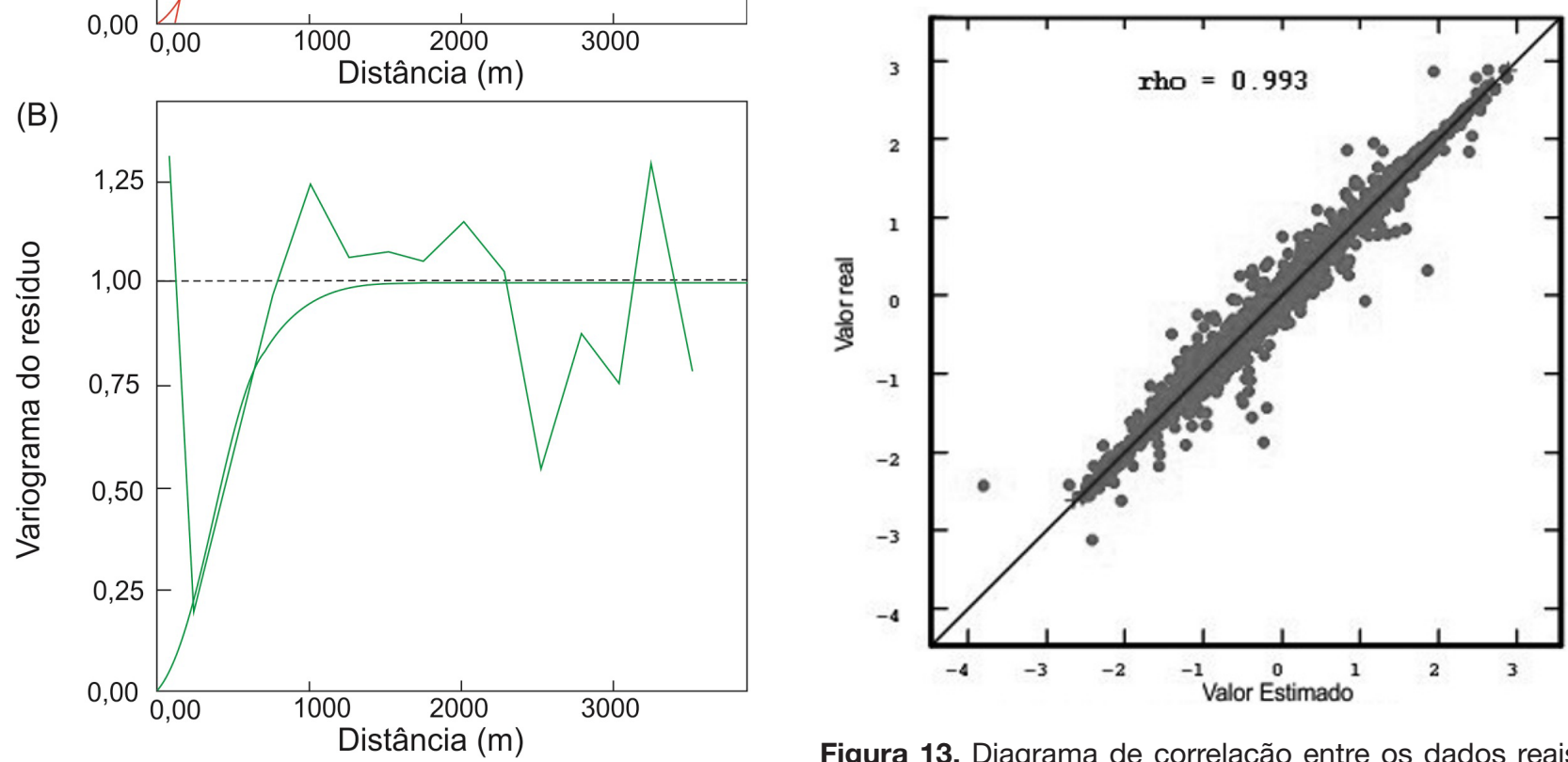

Figura 13. Diagrama de correlação entre os dados reais e os dados estimados pelo variograma médio calculado para o bloco.

menos. Nas imagens do início do enchimento, observam-se duas regiões distintas em termos de cotas. À medida que ocorre o enchimento do lago, valores elevados de cota potenciométrica são visíveis também nas porções centrais da imagem. Os perfis verticais da Figura 16A, B permitem visualizar o processo no decorrer do tempo e foram obtidos de uma realização escolhida aleatoriamente.

Os perfis verticais permitem observar a progressão do impacto do enchimento do reservatório no nível freático. É possível afirmar que as duas populações 1 e 2 , inicialmente muito densas e representadas pelas cores extremas vermelhas $\mathrm{e}$ azuis, se espalham pelo terreno de maneira heterogênea. Ao final do processo, pode-se observar uma rápida homogeneização dos valores, agora em tons mais azulados de cotas mais altas. Isto representa o equilíbrio hidráulico sendo estabelecido após o término do enchimento do reservatório. 
Tabela 6. Dados estatísticos das simulações n॰ 18 e n 65 que apresentaram maior contraste.

\begin{tabular}{lccccccccc}
\hline & Mín & Máx & Média & s & Var[x] & CA & $\mathbf{Q ( 2 5 \% )}$ & M & Q(75\%) \\
\hline Simulação 18 & 282,97 & 387,97 & 336,70 & 18,06 & 326,33 & $-0,35$ & 323,69 & 339,59 & 349,80 \\
Simulação 65 & 284,20 & 385,49 & 334,61 & 17,12 & 293,16 & $-0,28$ & 322,94 & 336,92 & 346,74 \\
\hline
\end{tabular}

Mín: valor mínimo; Máx: valor máximo; s: desvio-padrão; Var(x): variância; CA: coeficiente de assimetria; Q: quartil; M: mediana.
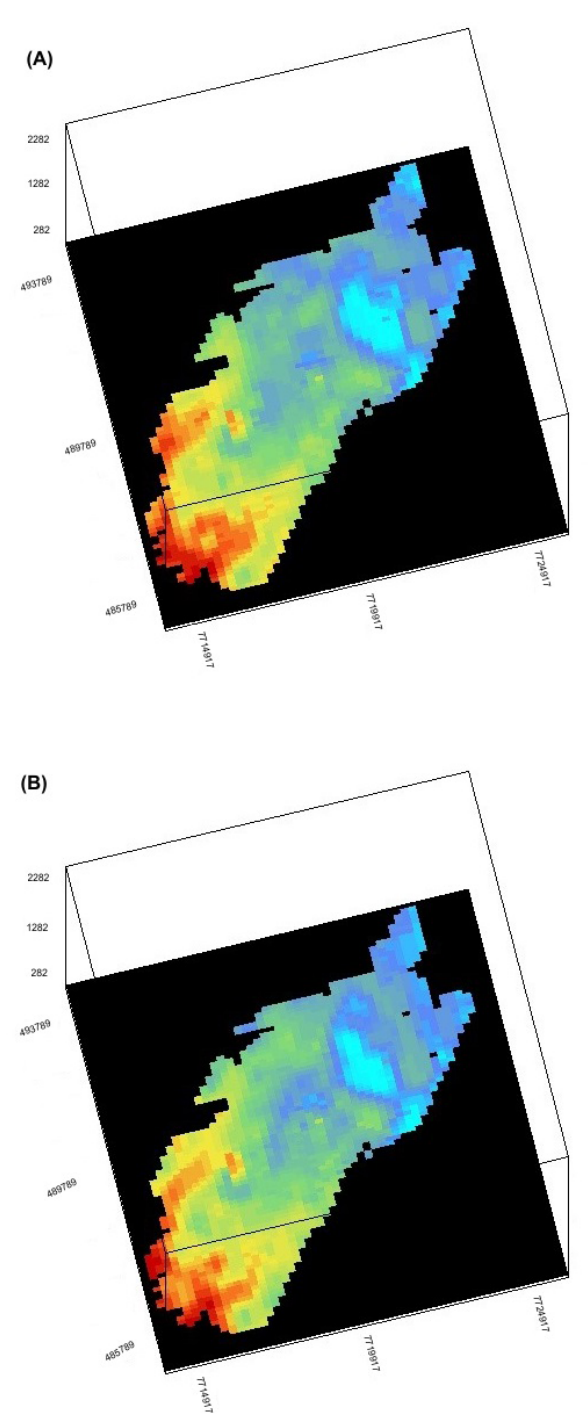

Figura 14. A) Mapa da realização n 18, correspondente ao início do enchimento do reservatório; B) Mapa da realização n 65 , correspondente ao início do enchimento do reservatório.

\section{Tratamento algébrico}

As imagens das duas simulações $\left(\mathrm{n}^{\circ} 18\right.$ e $\left.\mathrm{n}^{\circ} 65\right)$ foram tratadas para reforçar os contrastes existentes entre elas e atenuar os valores médios na imagem, o que resultou em uma imagem das variações entre as duas simulações, com amplificação das diferenças positivas.
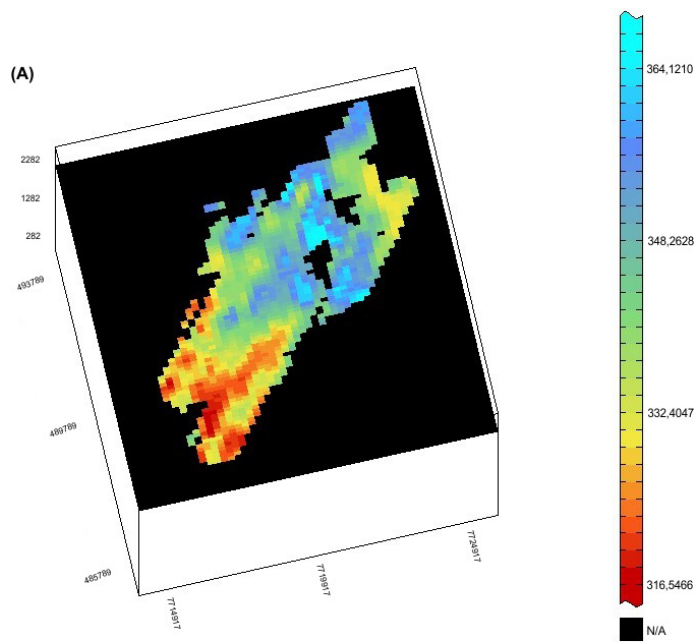

(B)
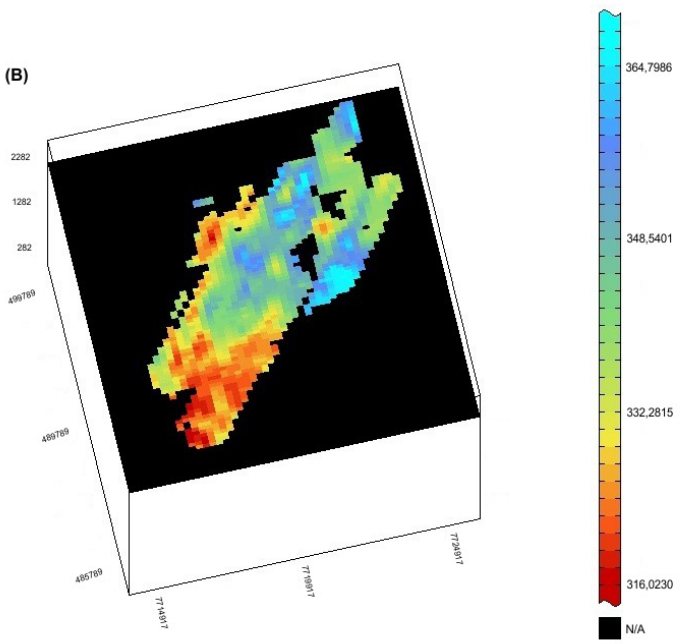

Figura 15. A) Mapa da realização $n^{\circ} 18$, correspondente ao final do enchimento do reservatório; B) Mapa da realização $n^{\circ} 65$, correspondente ao final do enchimento do reservatório.

A Figura 17 apresenta o mapa resultante desse tratamento algébrico. Em cores frias, estão representadas as maiores variações do nível potenciométrico, e em cores quentes, as menores. Em (A), temos o mapa de variação para a situação inicial, antes do enchimento, e em (B), a situação final.

Observa-se que existe aumento nas variações do nível potenciométrico, registrado na Figura 17B, na porção NE do mapa ao final do enchimento, quando comparado com o mapa visto em (A). A porção centro-sudoeste representa uma região de menores variações, com inúmeros espaços vazios e cores quentes, lembrando que espaços vazios representam regiões onde a elevação é menor que a elevação média. 

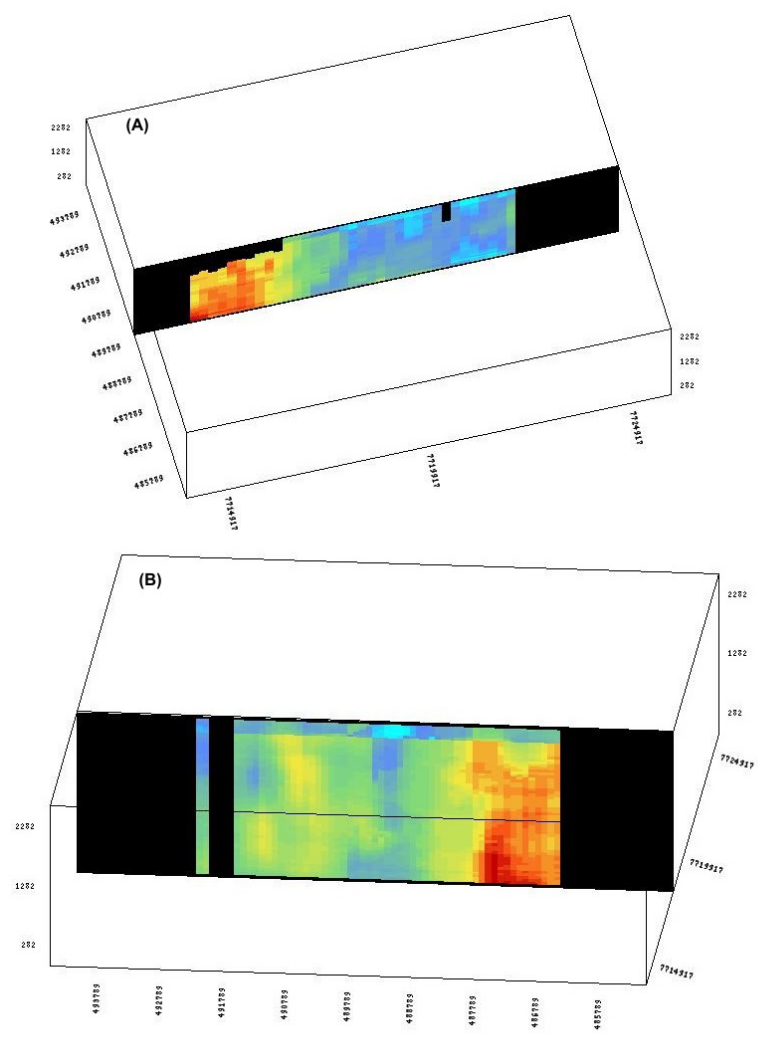

Figura 16. A) Perfil vertical $X Z$ do modelo de blocos: o eixo vertical ( $\mathrm{Z}$ ) representa o tempo no processo de enchimento do reservatório em sua direção ascendente; B) Perfil vertical YZ do modelo de blocos: o eixo vertical (z) representa o tempo no processo de enchimento do reservatório em sua direção ascendente.

\section{CONCLUSÕES}

O valor do método aplicado deve-se principalmente ao controle matemático dos fenômenos, com a precisão que a simulação oferece, quantificando e servindo de ferramenta à geologia de engenharia em análises de impacto hidrogeológico do enchimento de reservatório, auxiliando na tomada de decisões que visem à mitigação de possíveis danos.

A análise das variações do nível de água efetuada identificou o progressivo aumento das cotas, saindo de uma situação homogênea e bimodal dos valores, com cotas baixas a SW da área, e valores altos a NE desta, passando por desequilíbrio hidráulico durante o enchimento do reservatório e, finalmente, chegando a uma situação de equilíbrio com cotas mais altas, sobretudo na porção NE da área. Pelo tratamento de imagens, a região NE da área estudada foi identificada como aquela com maior risco de elevação do nível freático. Por sua vez, a porção centro-SW apresenta as menores variações, representando menos riscos.
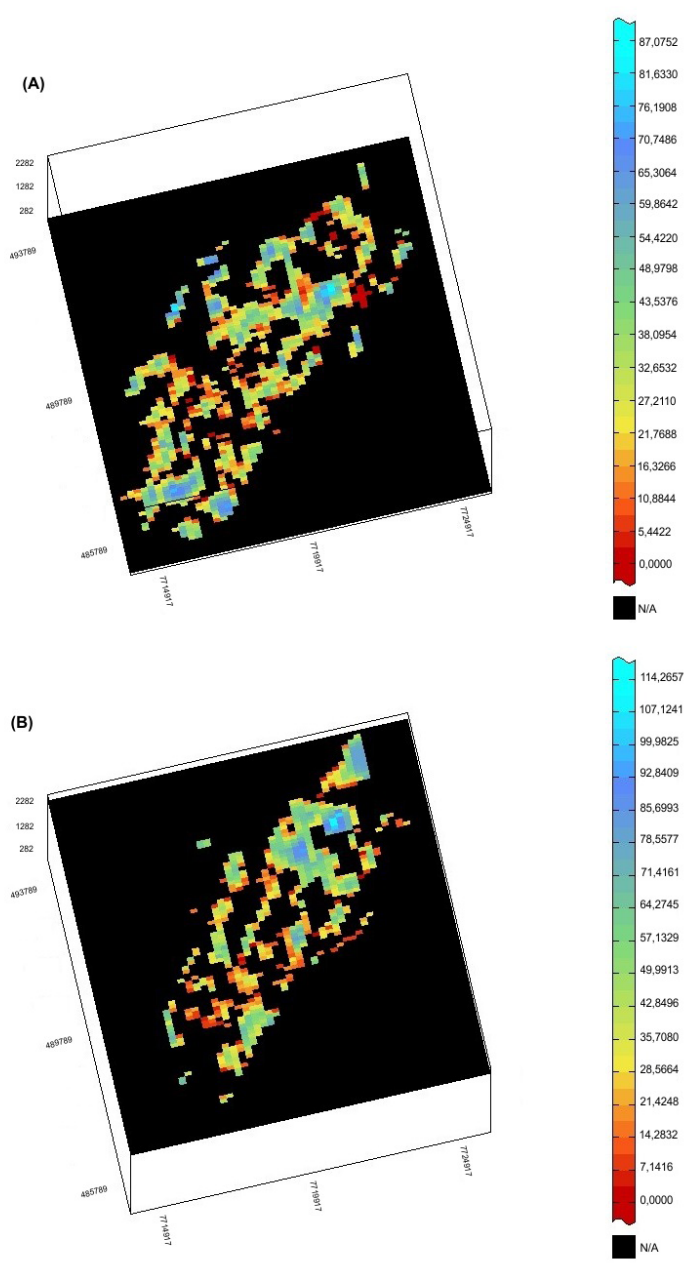

Figura 17. Mapa de variações do nível potenciométrico após tratamento algébrico. Em (A), temos o mapa de variações do início do processo de enchimento e, em (B), o mapa de variações do final do processo.

A realização da análise de risco pelo método de Simulação Estocástica por Bandas Rotativas demonstrou grande compatibilidade com a elaboração de estudos temporais do nível freático no entorno do reservatório da barragem de Três Irmãos, em Pereira Barreto, indicando a perfeita adequação da metodologia, que poderá ser melhorada e consolidada com base em novos estudos associados a outros reservatórios.

\section{REFERÊNCIAS}

Albuquerque Filho, J. L., Leite, C. B. B. (2002). Elevações induzidas no lençol freático devido a formação de reservatórios e o significado das modificações resultantes. Revista: Universidade Guarulhos, 7, 69-74. 
Armstrong, M. (1998). Basic linear geostatistics. Berlin: Springer-Verlag.

Deutsch, C. V., Journel, A. G. (1992). GSLIB - Geostatistical software library and user's guide. New York: Oxford University Press.

Instituto de Pesquisas Tecnológicas do Estado de São Paulo (IPT). (1983). Avaliação do efeito do reservatório de Três Irmãos sobre o nível piezométrico regional: primeira fase, v. 2, 19 p. São Paulo: IPT. (Relatório n. 18.760).

Kitanidis, P. K. (1997). Introduction to geoestatistics: applications in hydrogeology. Cambridge: Cambridge University Press.

Leite, C. B. B. (2005). Avaliação do impacto do reservatório de Três Irmãos sobre a superfície potenciométrica do Aquifero Livre na cidade de Pereira Barreto (SP): uma abordagem numérica e geoestatística. Tese (Doutorado). São Paulo: Instituto de Geociências e Ciências Exatas - UNESP.

Lourenço, D. A. (2005). Geoestatística aplicada aos dados de potenciometria do reservatório de Três Irmãos, Pereira Barreto - SP. Monografia (Trabalho de Conclusão de Curso). São Paulo: Instituto de Geociências - USP.

Medovar, Y. A., Akhmetyeva, N. P. (1984). The reservoir effect on hydrological conditions of share areas of the Ivankovo reservoir. Environmental Geology, 5(4), 219-224.

Rocha, M. M., Lourenço, D. A., Leite, C. B. B. (2007). Aplicação de krigagem com correção do efeito de suavização em dados de potenciometria da cidade de Pereira Barreto SP. Geologia USP, Série Cientifica, 7(2), 37-48.

Yamamoto, J. K. (2001). Avaliação e classificação de reservas minerais. São Paulo: Edusp. 